\title{
Paradigmas normativos para la organización documental en los albores del siglo XXI
}

\author{
ROBERTO GARDUÑO VERA \\ Centro Universitario de Investigaciones Bibliotecológicas \\ Universidad Nacional Autónoma de México, 04510 \\ México D.F., Tel: (525)623-03-45 \\ E-mail: garduno@ servidor.unam.mx
}

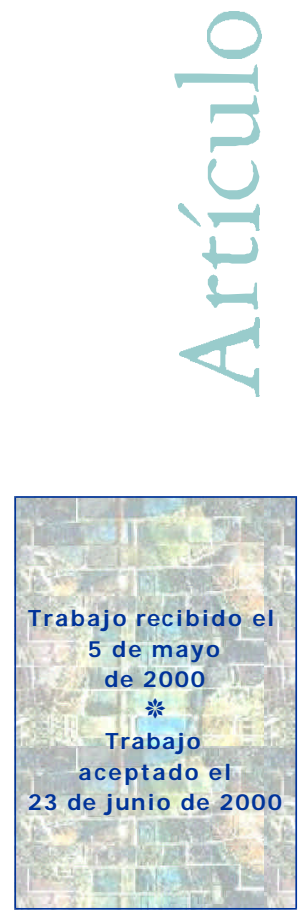

\section{RESUMEN}

Se abordan diversos fenómenos involucrados con la organización documental ocasionados por el desarrollo de tecnologías de información y comunicación. Se analiza la función del modelo generado por los formatos bibliográficos cuya génesis se relaciona con las tecnologías aparecidas en los sesentay se estudia su evolución tras integrar las tecnologías de los ochentay los noventa. Se analiza también el paradigma creado por los formatos digitales aplicado al ámbito de la organización de la información digitaly sus repercusiones en los medios bibliotecarios en los inicios del presente milenio.

En este contexto, se estudia el contenido de la Iniciativa del Núcleo de Dublín (Dublín Core. DC) y sus posibles repercusiones en los ambientes bibliotecarios. Se presenta información relevante sobre el Proyecto Nórdico de Metadatos y el seguimiento y aplicación que ha realizado del DC, y se concluye examinando las diversas posibilidades que tienen los sectores bibliotecarios para participar en las actividades que requiere la organización de la información digital disponible en redes.

Palabras clave: Normalización; Organización documental; Metadatos.

\section{NORMATIVE PARADIGMSOF DOCUMENTAL ORGANIZATION AT THEL BEGINING OF THE XXI CENTURY ROBERTO GARDUÑo-VERA}

\begin{abstract}
Diverse phenomena resulting from the development of information and communication technology and their effects on the organization of documentation are approached. The function of the model generated by the bibliographic formats, whose creation is related to seventies era technology, is analyzed. The model's evolution with the emergence of new technologies of the eighties and nineties is also studied. The digital format paradigm as applied to the field of digital information organization and its repercussions in the media of Library Science is also analyzed.
\end{abstract}


Within this context, the Dublin Core (DC) and its possible repercussions in the field of Library Science is studied. Relevant information on the Proyecto Nordico de Metadatos (The Nordic Meta-data Project) is presented, as well as a dscussion of the follow up and application that the DC has carried out. The paper concludes with an examination of how Library Science professionals might be involved in the organization of digitized information on the world-wide web.

Key Words: Standarization; Documental organization; Metadata.

\section{INTRODUCCIÓN}

L a historicidad de la organización de la información indica que en el transcurso de los siglos, la sistematización del conocimiento para su posterior localización, recuperación y utilización, ha sido fundamental para el desarrollo cultural dela humanidad: organizar para, posteriormente, difundirinformación aindividuos 0 a grupos de una sociedad dada es un fenómeno que se repite en el tiempo yen el espacio. En consecuencia la organización de los registros gráficos, producto del quehacer intelectual del hombre, ha sido una actividad constante a través de las épocas y en toda sociedad.

Alcanzar una organización documental apropiada que facilite la recuperación de la información ha suscitado que en cada época los estudiosos se dieran a la tarea de generar técnicas y normas que facilitaran la realización de tal empresa. En este contexto, se advierte que los desarrollos tecnológicos generados a partir de 1960 se han orientado a la búsqueda de mayor eficacia en el almacenamiento, la recuperación, la transferencia y el uso de la información. En consecuencia, la incorporación de esas tecnologías en tareas relacionadas con la organización documental ha requerido la generación de herramientas normativas apropiadas que faciliten la descripción de la información documental en diversos medios tecnológicos.

Es evidente que el desarrollo de las normas generadas en los ambientes bibliotecarios representa un cúmulo de conocimiento en materia de organización de la información; sin embargo los hechos indican que su automatización ha requerido, desde 1965, la incorporación de formatos bibliográficos como componentes indispensables de las herramientas de apoyo para la normalización documental. Es indudable que en el presente milenio dichos formatos seguirán desempeñando un papel relevante en la organización de información bibliográfica dada la constante generación de software y bases de datos apoyados en las estructuras de formatos bibliográficos, principalmente la del formato MARC.

Sin embargo, la aparición y constante aumento en Internet derecursos informativos de carácter científico y técnico ha puesto de manifiesto la necesidad que tenemos de contar con otras herramientas que faciliten la descripción y recuperación de recursos digitales. Es esto lo que ha propiciado la generación lenguajes de marcado denominados también lenguajes digitales. 
Los hechos indican que en la actualidad la descripción de la información digital con base en el lenguaje HTML (HyperTextMarkupLanguaga) requiere la utilización de herramientas normativas complementarias que ayuden a evitar la inconsistencia en esa descripción. Sin embargo, la sintaxis de dicho lenguaje carece de algunos de los elementos que son necesarios para representar información estructurada. Por otra parte también se acepta que la sistematización de recursos digitales es determinante para construir metadatos, bibliotecas digitales y pasarelas temáticas.

No obstante que diversos estudiosos prevén la sustitución de los formatos bibliográficos por los formatos digitales, los hechos indican que, en los albores del presente milenio, la aplicación de formatos bibliográficos en tareas de sistematización documental continúa reteniendo mucho valor entre las comunidades bibliotecarias. Asimismo se advierte que la apropiación del conocimiento relacionado con los formatos digitales y sus implicaciones en tareas de sistematización documental es un requisito indispensable para el bibliotecario.

Un aspecto importante que puede ser rescatado del cúmulo de experiencia logrado con la aplicación de formatos bibliográficos en los medios bibliotecarios, es la intención de evitar la "clonación" de estructuras de formatos digitales, fenómeno que ha surgido con el uso de formatos bibliográficos (por ejemplo, la aparición de un sin número de formatos "marcoides")1. Lo anterior ha ocasionado, en muchos casos, diversos problemas: duplicidad de esfuerzos en la generación de registros bibliográficos; altas inversiones en software; gastos no previstos de programación para hacer compatibles los registros entre diversos formatos, e inhibición en la cooperación para el intercambio de registros bibliográficos.

\section{MODELO CREADO CON LA APARICIÓN DE FORMATOS BIBLIOGRÁFICOS}

El paradigma creado a partir de 1965, con la aparición de formatos bibliográficos, marcó un acontecimiento en los medios bibliotecarios porque obligó a los profesionistas de esta área a reorientar la aplicación de herramientas normativas utilizadas tradicionalmente hacia tareas de organización bibliográfica. Los bibliotecarios se percataron de que utilizar una nueva herramienta requería la adquisición de nuevos conocimientos para poder realizar tareas de descripción documental inducidas por la estructura delos formatosy por los paquetes de programas de cómputo de aplicación.

Es notorio que a partir de los años sesenta, cada época ha ido determinando a los medios bibliotecarios: sus requerimientos de conocimiento tecnológico y el desarrollo de habilidades para su manejo. Así, el formato MARC surge con la tecnología de los sesenta, UNIMARC con la de los setenta y el CCF con la de los ochenta. Las características de cada época se ven reflejadas en las estructuras de los formatos, principalmente

1 Se han denominado marcoides a los formatos basados en MARC y que no contemplan su estructura formal. 
en lo que se refiere al manejo de relaciones lógicas entre los contenidos de los registros bibliográficos codificados con base en cada formato.

La estructura de los formatos señalados, pese a sustentarse en campos de longitud fija y longitud variable, los hace diferentes debido a que mientras los formatos MARC yUNIMARC apoyan su estructura en las Reglas de Catalogación Angloamericanas (segunda edición), o en las Normas Internacionales para la D escripción Bibliográfica (ISBD ), respectivamente, el formato CCF, aunque recomienda para su implementación las normas ISBD , no supedita su estructura a ellas; más bien permite un alto grado de flexibilidad y manejo libre de lainformación. El uso de relaciones lógicas entre campos de un mismo registro o con diversos campos de otros registros determina un alto grado de flexibilidad sustentada en tecnologías más modernas.

El paradigma subyacente en los formatos bibliográficos tiene como intención fundamental señalar que un formato de esta naturaleza conlleva, en la práctica, un conjunto de decisiones semánticas y formales relacionadas con el grupo de elementos utilizados para describir documentos de tipo específico. Asimismo, resalta el método de organizar información bibliográfica de modo que los elementos fundamentales puedan describir documentos para ser identificados a través de computadora.

Las funciones de los formatos bibliográficos como los arriba señalados, han sido fundamentales para hacer representaciones estructuradas de registros bibliográficos en ambiente automatizado, para intercambiar estos registros entre unidades de información y para orientar el diseño de bases de datos bibliográficos.

D esde 1965, el uso de formatos bibliográficos le ha mostrado a las comunidades bibliotecarias que poder ser éstos aplicados en las tareas mencionadas exigía que los elementos que se utilizaran deberían estar de acuerdo con los intereses informativos de los sectores sociales (usuarios de bases de datos), por lo que tales elementos deberían ser claros, consistentes y unívocos, pues ello facilitaría su aplicación. A simismo, su incorporación a tecnologías de información requería el uso de esquemas de codificación que se vieran reflejados en los códigos, etiquetas, indicadores y códigos de subcampo considerados en la estructura de los formatos bibliográficos cuyo destino es cumplir con los requerimientos tecnológicos, y facilitar así la descripción, el control y laintegridad en el manejo de registros bibliográficos, así como allanar su uso.

La experiencia adquirida por los bibliotecarios en el uso de formatos bibliográficos, ha mostrado que en los inicios del 2000 se comprende con mayor certeza que cada uno de los códigos y etiquetas de los formatos contienen elementos para codificar, en forma unívoca y libre de ambigüedades, cualquier dato que requiera la organización bibliográfica automatizada. En consecuencia, las relaciones que se establecen entre los elementos estructurales de un formato de esta naturaleza pueden ser de forma (con base en códigos y etiquetas) y de contenido (atendiendo al significado de los datos que representa cada código y cada etiqueta), relaciones que sustentan la base lógica para construir estructuras de almacenamiento y recuperación de información bibliográfica. 
Lo anterior ha mostrado en los hechos que un sistema bibliográfico automatizado se constituye tomando como base la estructura de codificación para el almacenamiento y la recuperación de datos que muestren relaciones de contenido lógico entre los distintos códigos. De esta manera la estructura de codificación se hace explícita por medio de códigos de formato, en tanto que las relaciones lógicas se expresan en forma de índices o procesos de búsqueda. En este sentido, cualquier etiqueta, indicador o código de subcampo son considerados como códigos de formato, cuya función obedece a las particularidades de contenido y de procesamiento de los registros bibliográficos.

El uso de técnicas de automatización relacionadas con formatos bibliográficos fue desde sus inicios una propuesta novedosa para los sectores bibliotecarios y por tanto el predominio de dichosformatos en la automatización de registros, en el diseño de bases de datos y en el intercambio de información bibliográfica ha sido determinante para los medios bibliotecarios del mundo desde 1965. Los hechos indican que en el presente milenio este tipo de formatos (principalmente MARC) continuará teniendo un amplio uso en el desarrollo de las actividades mencionadas.

O tro aspecto importante a considerar respecto de la no inmediata obsolescencia de los formatos bibliográficos se refiere al cúmulo de experiencia adquirida en los sectores bibliotecarios einformáticos en cuanto a la automatización de información bibliográfica apoyada en normas internacionales, y al aumento en la generación de bases de datos bibliográficos que se basan en algunos de estos formatos. Así, no obstante la reciente aparición de formatos de marcado para ser empleados, entre otras tareas, en la organización de documentos digitales, no será fácil quelos medios bibliotecarios adopten rápidamente estos nuevos formatos que aún se encuentran en sus inicios de aplicación y no han probado hasta ahora su eficacia en la sistematización normalizada de información digital a gran escala.

Los hechos indican que el formato MARC ha sido vinculado con las diversas tecnologías aparecidas en distintas épocas, aspecto que se refleja en los productos basados en este formato como; Bibliofile en medio láser, el catálogo en línea dela Biblioteca del Congreso de los Estados Unidos, y la generación de un sistema de catalogación basado en inteligencia artificial (el cual no tuvo mayor trascendencia). En la actualidad dicho formato es analizado con la intención de incorporarlo a sistemas de manejo de metadatos.

En octubre de 1999 fue liberada la información más actual relacionada con los avances de la investigación sobre los elementos bibliográficos base MARC $21^{2}$ que

2 MARC 21 contiene laversión conjunta deUSMARC yCANMARC, la información más reciente pue de ser consultada en:

Dublín Core/ MARC/ GILS Croswalk. http:/ / www.loc.gov/ marc/ dccross.html 
serán el fundamento para realizar el "mapeo" con los atributos y la sintaxis del Núcleo de D ublín, así como con los de diversos sistemas de información. Como las investigaciones están en sus inicios continuar con el estudio teórico y probar en su momento su aplicación a gran escala será una tarea fundamental para el siglo XX I.

Sin embargo, este siglo perfila también la consolidación y aparición de otras tecnologías, lo que indica que los especialistas en organización documental continuarán experimentando y aplicando nuevos desarrollos tecnológicos relacionados con la sistematización de documentos que puedan facilitar la integración de sistemas de información remotos y la intercomunicación de los sujetos que intervienen en los procesos del conocimiento publicado en cualquier medio físico.

\section{PARADIGMA CREADO CON LA APARICIÓN DE LENGUAJES DE MARCADO PARA LA REPRESENTACIÓN DE RECURSOSDIGITALES}

Eldesarrollo tecnológico de los noventa trae consigo la posibilidad de presentary transmitir textos digitales a través de las redes mundiales de telecomunicación, y facilitala incorporación al texto electrónico dela presentación hipertextual, la imagen, el sonido y el movimiento a través de Webs, posibilidades que han generado otras formas de catalogación y la clasificación de información digital.

Todo indica que el uso de tecnologías de información y comunicación en los medios bibliotecarios continúa modificando las tareas relacionadas con la organización documental, la integración de sistemas remotos de información y la intercomunicación entre autores, editores, distribuidores, bibliotecarios, documentalistas, especialistas en tecnologías de información y usuarios finales de ésta.

Lo anterior se hace visible a partir de la orientación de diversos programas relacionados con la edición y la organización digital de datos cuya intención es integrar globalmente a los actores de conocimiento publicado con las unidades de información. Esto pretende reducir las barreras tecnológicas que pueden presentar las telecomunicaciones y facilitar el uso de normas internacionales en el campo de la comunicación de información digital. En este contexto, la posibilidad de generar flujos de información en un marco global requerirá, en su momento, dela sistematización de los contenidos deesos flujos, lo cual necesariamente habrá de incidir en el uso de normas de catalogación y clasificación.

En este entorno tecnológico aparecen después de los años noventanuevas directrices parala representación delainformación digital. Los formatos SG ML (Standard GenealisedMarkupLangagę y el HTML (HyperTextMarkupLangrage), surgen como propuestas pioneras para representar información de esta naturaleza. El modelo propuesto por los formatos digitales tiene como propósito estructurar la sintaxis en la que seráincorporadala representación de la información digital disponible en redes. En este contexto, el formato se refiere a la identificación de los elementos 
(etiquetas) que permiten definir los campos en donde pueda ser representada la información "digital."3

D espués del surgimiento de los lenguajes SG ML yHTML, han aparecido otros lenguajes digitales tales como elX ML (eX tended Markup Lenguaje) cuyo propósito es fa cilitar la representación de documentos electrónicos disponibles en Webs y potenciar sus posibilidades de relaciones con otros recursos informativos para enriquecer la recuperación de información con base en los intereses de usuarios específicos.

\section{ESTRUCTURAS PARA LA ORGANIZACIÓN DE RECURSOS DE INFORMACIÓN DIGITAL}

\section{Formato $H T M L$ ( $H$ ypertext $M$ arkup $L$ anguage $=$ Lenguaje de $M$ arcado para H ipertexto)}

El Lenguaje de Hipertexto basado en Marcas (HTML) se asume como un lenguaje universal cuyo propósito es clasificar los elementos característicos de documentos digitales con la intención de facilitar su recuperación y su visualización en diversas plataformas.

Así, el hipertexto se refiere al contenido que pueda tener un documento considerando las características de formato, texto, imagen, sonido y voz (multimedios), a los enlaces que existan entre las partes del propio documento y a los vínculos que se establecen internamente con otros documentos afines en términos temáticos. Las marcas son símbolos (etiquetas) que se incorporan a las partes que constituyen el documento con el fin de identificarlo como objeto, y su incorporación a las diversas partes de un documento puede realizarse atendiendo a la simplicidad o complejidad del análisis descriptivo que se requiera lograr. En consecuencia, es factible describir sólo los elementos catalográficos que identifican de manera general al documento, o catalogar y clasificar su texto completo para posteriormente hacer usos múltiples del contenido.

Por tanto debe entenderse que el HTML es un lenguaje de marcas utilizado para clasificar las partes que estructuran a los documentos, para lo cual utiliza una sintaxis preestablecida que facilita la clasificación en web de la información digital. Warren Steel ${ }^{4}$ señala al respecto lo siguiente:

"Un autor Web no es un programador, ni un tipógrafo, ni un diseñador gráfico. D esde los días de Gutemberg, los autores han podido desprenderse de su preciado trabajo al desarrollar un manuscrito que se va a publicar. Los manuscritos de los autores pueden incluir capítulos, párrafos, títulos, tablas e ilustraciones, todas correctamente marcadas, pero es el editor el que elige el papel, el diseño de páginas, las

3 Lo digital se refiere a las características tecnológicas en las que se vierte la representación de elementos para identificar y recuperar información digital utilizando valores discretos de 0 y 1.

4 Warren Steel. [en línea] "Trucos para nuevos autores".

http:/ / wwwmcsr.olemiss.edu/ mudws/ web

hintshtm. En HTML 4.0/ E. Stephen MackyJanan Platt. Madrid : Anaya Multimedia, 1998. p.51. 
fuentes y otras características, de acuerdo con el "estilo de la casa". Del mismo modo, un autorWeb prepara un documento mediante el marcado de sus elementos y "se lo envía al editor" colocándolo en un servidor Web. La función del editor es compartirlo entre el explorador que interpretará el texto y los gráficos sobre el hardware disponible, y los seres humanos que verán el documento. Es el usuario el que configura al explorador eligiendo las fuentes, tamaños, coloresy otras características de la apariencia en pantalla".

En este sentido, la World Wide Web permite la organización de documentos digitales en modo de hipertexto. El hipertexto se sustenta en métodos de organización de la información a través de los cuales los diferentes elementos del contenido pueden ser ligados por medio de los elementos del propio contenido. Lo anterior determina la intervención del bibliotecario en la fase de organización normalizada de los documentos digitales existentes en Web, lo cual remite a una tarea novedosa en el sentido de que se tienen que enfrentar, entre otros aspectos, con el manejo de documentos en modo de hipertexto, lo cual remite a información almacenada en forma digital con vínculos de referencias hacia sitios web. D e este modo se puede avanzar de un recurso informativo a otro, navegar por el texto y obtener información con base en los intereses específicos del usuario final de la información.

En este contexto el lenguaje HTML constituye una herramienta útil debido a que facilita el diseño, la catalogación y la clasificación de documentos digitales con base en marcas predefinidas (etiquetas), las cuales se añaden a los documentos que se almacenan en laWWW. Esto permite la presentación gráfica de los documentos, incluyendo vínculos entre páginas del mismo web y otros recursos digitales remotos. El diseño gráfico de los recursos informativos se refiere a su presentación, lo cual incluye: etiquetas HTML, contenido del documento, separación de párrafos, resaltados especiales, resaltados de títulos, conceptosy términos relevantes, subrayado de partes específicas, color de fondo o color de las partes componentes, comentarios, saltos de párrafo, identificación de citas, tamaño de letras, listas de términos, identificación de imágenes, determinación de sonido y ligas multimedia, entre otros atributos.

En consecuencia, se advierte que el HTML tiene dos funciones básicas:

1. Formalizar a través de etiquetas la presentación de documentos digitales parafacilitar su recuperación a través de Internet.

2. O rientar al navegador a partir de las etiquetas para que interprete, recupere y rea lice la presentación del documento digital en pantalla.

Lo anterior puede tener repercusiones en los procesos de organización de información de esta naturaleza, por tanto se advierte que acceder al conocimiento y al manejo de dicho lenguaje y de las tecnologías relacionadas, puede propiciar beneficios en el ciclo almacenamiento, organización, recuperación y uso de lainformación digital. 
Paradigmas normativos para la onganización documental en los albores del siglo... 123

\section{Lenguaje SG ML (Standard G eneralized M arkup L anguage = Lenguaje Es- tándar G eneralizado de M arcas)}

El SGML fue establecido por la Organización Internacional de Normalización (ISO ) con la pretensión de unificar la aplicación de los conceptos de anotación estructurada. Fue concebido como un metalenguaje (lenguaje de lenguajes) a través del cual se pueden definir lenguajes prototipo para el marcado de elementos que identifiquen documentos digitales. Se ha señalado que el SGML tiene tres características principales:

1. El estándar de SGML no incluye información sobre cómo deben ser interpretadas las anotaciones. Su principal objetivo es describir las unidades lógicas de un documento.

2. El concepto de tipos de documentos. SG ML determina la noción "Tipo de D ocumento" (DoumentTypeDefinition=DTD ), con el propósito de verificar si un documento tiene valor absoluto como objeto o es miembro de una clase determinada.

3. SGML evita la dependencia de los conjuntos de caracteres tales como ASCII, en general utiliza caracteres definidos en casi todos los sistemas y determina mecanismos para emplear caracteres especiales o poco comunes. ${ }^{5}$

Algunas características del SG ML se refieren a la capacidad para independizar la plataformay el procesador de texto, y alaindependencia que tiene el conjunto de caracteres tomando en cuenta las características del equipo que se utiliza; esto permite migrar en forma transparente de una computadora que utilice caracteres ASCII Extendido a otra que reconozca UNICODE o especificaciones de la norma ISO / IEC 8859-1:1998 Information Technology-8 byte Coded G raphic Character Set.

En la actualidad el SG ML se ha convertido en una norma de suma importancia para la industria tecnológica y ha influido en la generación y modificación de productos comerciales como es el caso de Word, en el que se han considerado diversos parámetros del SG ML para hacerlo más versátil. Asimismo, el HTML de laWWW ha heredado múltiples características del SGML.

\section{Formato X ML ( $\mathrm{eX}$ tensible $\mathrm{M}$ arkup L anguage $=$ Lenguaje $\mathrm{G}$ eneralizado de Marcado)}

La publicación de la primera versión del lenguaje XML apareció en noviembre de 1998, sin embargo se hizo notar en el mercado delas tecnologías de información debido al interés mostrado por Microsoft y N etscape. X ML es un subconjunto simplificado del estándar SG ML de ISO que contempla parámetros para hacer operar aplicaciones Intranet demaneraágily quetiene un alto grado de eficiencia. Su aplicación en ellas se propone:

5 Beatriz Juárez Santamaría y M. Patricia Martínez O rtega. Mładatos México : UNAM, Facultad de Filosofíay Letras, Posgrado de Bibliotecología. 1999. p.8. (Trabajo presentado en el Seminario sobre Normalización de la Información D ocumental) 
* Lograr que los datos de Intranets sean fáciles de gestionar.

* Desarrollar aplicaciones de alta velocidad a través de mecanismos que permitan compartir procesos en diversos equipos.

Por lo anterior se puede observar que la estructura de los formatos HTML, SG ML y XML, determina una lógica novedosa orientada hacia la organización de recursos digitales. En consecuencia los bibliotecarios requieren desarrollar habilidades en la aplicación de dichos formatos y de las tecnologías de información complementarias a ellos. Sin embargo, el mundo bibliotecario ha adquirido a través delos formatos bibliográficos un cúmulo de experiencia que con toda seguridad les será de mucha utilidad para apropiarse de la lógica y el manejo de los formatos digitales; los cuales, se advierte, estarán en auge en el presente milenio.

Conviene tener presente que con fundamento en los formatos mencionados en el párrafo anterior, es factible incorporar a la web información muy variada; no obstante, esa variedad puede dar lugar a inconsistencias en caso de no prever mecanismos de normalización y organización apropiados. A demás el uso de tecnologías de información en tareas de sistematización documental obliga a considerar como partes de ella a la preservación y a la conservación de colecciones documentales, puesto que el medio digital puede determinar características de organización, preservación de contenidos y lineamientos de recuperación.

Lo anterior remite necesariamente a un análisis profundo de las características y contenidos de la información digital que requiera ser sistematizada para su uso local y global; de las normas que sustentarán tal organización; de los medios en que será almacenada y de los mecanismos tecnológicos que serán necesarios para su recuperación. No obstante la existencia de diversas propuestas para la organización de información digital, es evidente que las actividades implicadas se encuentran en sus inicios, en consecuencia la participación de los medios bibliotecarios es determinante porque nos encontramos ante un fenómeno que requiere de conocimiento y experiencia en tareas de organización documental, y en esto los bibliotecarios tienen mucho que aportar.

\section{METADATOS: PARADIGMA ORIENTADO A LA DESCRIPCIÓN Y AL ACCESO DE RECURSOS DIGITALES}

Los hechos indican que a partir del incremento en la aplicación de formatos digitales se acentúa el uso de términos tales como biblioteca sin paredes (Browin, 1993); biblioteca electrónica (Barker, 1994); biblioteca virtual (Barker, 1994); biblioteca del futuro (Morales, 1996); biblioteca digital (K uny, 1998), y sistemas de metadatos. Los especialistas en tecnología de información y telecomunicación pronto se percataron que el desarrollo de este tipo de entidades requería de referentes que permitieran la objetivación de la información digital. A lo anterior se añadió el problema que presentaba la información al tratar de ser localizada a través de Internet. 
Una consecuencia de lo anterior fue el interés por estudiar las posibilidades que podrían ofrecer los metadatos, considerados como el conjunto de elementos que pue den generar una semántica internacionalmente aceptada con el propósito derepresentar la información digital, evitar su dispersión a través de una sistematización apropiada y asegurar su recuperación. D e manera general se pude señalar que los metadatos representan, por una parte, datos acerca de recursos informativos disponibles en redes, y contienen, por la otra, los elementos útiles para facilitar laidentificación y localización de recursos digitales. En consecuencia los metadatos deben considerar el contenido, la condición, la cualidad y la calidad, entre otras características, de la información digital.

A este propósito Rachel Heery ${ }^{6}$ señala lo siguiente:

Metadato se refiere a 'datos acenca de los datos.' Los registros catalográficos desarrollados en bibliotecas pueden ser considerados como metadatos en cuanto describen datos acerca de los datos. Similarmente, los registros de bases de datos, producto de los servicios de resúmenes e indización son metadatos (con algunas variantes). Por lo tanto, el término metadatos se utiliza cada vez más en el mundo dela información para referirse alos registros que relacionan los recursos electrónicos disponibles a través de redes.

En la reunión ELAG '97, se argumentó que metadato:

[...]se refiere a los atributos que describen a un objeto, los objetos pueden ser documentos tradicionales en bibliotecas tradicionales, o documentos disponibles en red [...] Un primer ejemplo respecto al uso del término metadato es en la catalogación tradicional realizada en bibliotecas, donde los metadatos se manifiestan como catálogos de tarjetas o registros bibliográficos. ${ }^{7}$

Sin embargo los hechos indican que la organización normalizada de la información disponible a través de Internet está aún latente, y se reconoce que ésta no es una tarea fácil y que en ella los bibliotecarios deben aportar su conocimiento y experiencia para ayudar a resolver los problemas inherentes a la organización y a la navegación en redes. Es oportuno tomar en cuenta que Internet no fue planeada como un soporte organizado parala recuperación de información, y si a esto se agregan el crecimiento exponencial de la información disponible en webs y el aumento de autores que publican sus productos de acuerdo con sus requerimientos, se comprende mejor el hecho de que diversos estudiosos de dicha red continúen considerándola como una colección caótica de múltiples recursos informativos. Sin embargo se prevé que el advenimiento de Internet 2 exigirá tanto una mayor precisión en la calidad de la información digital como en la organización normalizada de ésta.

6 Rachel Heeryl. "Review of metadata formats". En Program: automatedlibraryandinformation systems 30(4):345-346, oct. 96.

7 Metadata. ELAG' 97 ,

G dansk, June 18th 1997. http/ / uwwbibsysnd dag97/ maadatahtm 
En consecuencia los programas orientados a la organización de documentos digitales deben tener presente que la ubicación de un registro catalográfico existente en un catálogo en línea o en una biblioteca, se asocia, por lo general, con una determinada institución. Un registro de metadatos puede referir a una localidad remota, la que puede asociarse con una institución, con un autor o con un editor. Lo anterior indica que los recursos en red pueden residir en diversos sitios de Internet; en este sentido, los registros de metadatos pueden semejar un catálogo de unión que refiere a diferentes sitios de la red en los que se encuentren datos que refieren a su vez a otros datos que pueden contener información temática relacionada y relevante.

Respecto a la organización de recursos de información disponibles en Internet se han generado dos posturas, una señala que la indización y la catalogación pueden ser de mucha utilidad porque garantizan normalización en los registros, la otra asume que la organización de la información digital en redes debe ser diferente de la catalogación que se ha realizado tradicionalmente con el uso de normas bibliográficas, y advierte que bibliotecas y autores deben participar en la organización de este tipo de información.

No obstante lo anterior es necesario considerar que los recursos informativos de Internet crecen constantemente, que su uso tiende a incrementarse, que se introducen con frecuencia nuevas versiones de documentos, y que éstos pueden moverse de localidad en la red o ser renombrados o retirados sin aviso previo.

En este sentido, el beneficio de usar un nuevo término para describir recursos disponibles en Internet, según Caplan:

[...] no significa apegarse al término metadato como opuesto a la connotación tradicional de un registro bibliográfico. A cuñar un nuevo término debe enfatizar las diferencias inherentes a los registros que describan los recursos en red[.... $]^{8}$

Así, entre las características relevantes de los metadatos deben contarse su flexibilidad para formalizar vínculos y establecer enlaces entre recursos informativos digitales, para facilitar la recuperación de éstos a través de redes, para integrar en forma homogénea fuentes de información de toda naturaleza y para facilitar la compatibilidad entre diferentes formatos digitales y entre bases de datos en línea cuya estructura puede estar apoyada en algún formato bibliográfico.

Poner a disposición recursos documentales por medio de Internet resulta ser una tarea relativamente sencilla; sin embargo, organizar recursos informativos a gran escala, localizarlos, controlarlos y establecer usos múltiples de ellos, puede representar tareas muy complejas. Por tanto una tarea primordial de los especialistas en organización documental será definir las normas apropiadas y los elementos fundamentales

8 Priscilla Caplan. "Y ou call it corner, we call it syntax-independet metadata for document like objet". Citada por Heery Rachel. "Review of metadata formats". En Program automatedlibraryandin formation systems 30(4):346, oct. 1996. 
que ha de contener cualquier descripción digital en Internet. Sin embargo lo primordial debe ser que se le facilite al usuario final el acceso a la información relevante disponible en redes.

\section{INICIATIVA NÚ CLEO DE DUBLÍN METADATOS}

\section{Dublin C ore $(D C)=N$ úcleo de $D$ ublín}

El Núcleo de Dublín, surgió por la iniciativa del OCLC (O n Line Computer Library Center) y el NCSA (National Centre for Supercomputing Applications). Las reuniones iniciales de usuarios DC tuvieron como intención definir un conjunto de atributos que permitieran la objetivación de recursos disponibles en Internet.

La primearemiónoficial se realizó en Dublín, O hio en 1995 con la intención fundamental de identificar la semántica y los elementos fundamentales para describir recursos digitales en web. También se discutió en torno ala posibilidad de facilitarles a los editores y autores en general la elaboración de la descripción de sus documentos para incluirlos en páginas web. La identificación de elementos básicos también se propuso incidir en que los sitios de Internet dedicados a la indización de objetos lo hicieran con mayor eficiencia, y que las comunidades especializadas (bibliotecarios, documentalistas, etcétera) pudieran posteriormente incorporar un mayor número de campos y adecuarlos a sus requerimientos.

La segundaremiónse realizó en Warwick, Inglaterra y participaron especialistas del Reino Unido y de O CLC; las sesiones de trabajo versaron en torno a los aspectos siguientes:

* Sintaxis: Se acordó utilizar un formato de almacenamiento denominado D ocumento de D efinición de Tipos (DTD ), utilizando parámetros del lenguaje SG ML y la sintaxis del lenguaje HTML.

* Formato de almacenamiento Warwick: Se indicó que éste contemplaría los campos fundamentales de descripción y que también debería permitir ampliaciones orientadas a las comunidades especializadas, así como incluir elementos de carácter administrativo, términos, condiciones, etcétera. En esta etapa se definieron trece elementos básicos.

* Guía de usuarios: Se concluyó que la norma Warwick permitiría la interacción de diversos paquetes de programas de cómputo en el mismo formato de almacenamiento.

* Profesionales bibliotecarios. Se acordó que a partir de esta norma los bibliotecarios podrían incluir aspectos más específicos como calificadores o descriptores que pudieran representar adecuadamente los recursos digitales más complejos.

La tecera remiónconsideró la descripción de recursos visuales fijos como fotografías, archivos de imágenes y diapositivas. El equipo de trabajo acordó quelas normas y 
los elementos identificados en las primeras reuniones podían usarse para describir imágenes, pero agregó dos elementos para indicar el derecho de autor y el dominio computadora donde reside el objeto fuente. Así a los trece elementos existentes se les agregaron otros dos para sumar quince elementos fundamentales.

El arartogupode trabajo se celebró en Canberra, Australia, en 1997. D e esta reunión emergieron dos tendencias "filosóficas", la minimalista y la estructuralista:

Los minimalistas valoran la simplicidad por encima de todo, considerando que la aceptación y la interoperabilidad declinarán precipitadamente en cuanto la complejidad del estándar se incremente. Los estructuralistas admiten estos riesgos, pero también piensan que es esencial la complejidad para describir metadatos de contenido. En Canberra se definió el carácter de los modificadores necesarios, lo que constituyó uno de los principales resultados de este grupo de trabajo. ${ }^{9}$

El quintogupode trabajo del Núcleo de Dublín se realizó en Helsinki. Su finalidad era promover los elementos que aseguraran una alta efectividad en la organización y la recuperación de recursos digitales disponibles en Internet. El resultado de mayor importancia emanado de la reunión fue la aceptación de los quince elementos básicos del DC. En forma paralela se llevaron a cabo sesiones de trabajo para bibliotecarios, investigadores en bibliotecas digitales y especialistas en redes de teleproceso.

La octava reunión del DC se llevará efecto en Ottawa, Canadá en octubre del 2000, algunos temas a tratar serán los siguientes: generación de metadatos multilingües, políticas y requerimientos funcionales para hacer registros de metadatos, representación estructurada para creadores (autores), contribuidores, y elementos del editor, creación y administración de estructuras de autoridad, y Extensión del Núcleo de D ublín Metadata para dominios específicos de entidades de metadatos. Se espera una nutrida participación de los diversos sectores involucrados con la organización de recursos de metadatos.

El estándar DC consiste en un conjunto de elementos metadatos destinado a localizar con mayor facilidad recursos digitales apoyándose en la descripción de "O bjeto igual a D ocumento", la cual está desarrollándose como el núcleo de una gran actividad de investigación en el ámbito mundial cuyo propósito es producirun modelo capaz de describir la mayoría de los recursos disponibles en Internet como un todo, y ubicar en ésta los datos necesarios para describir recursos e identificar, procesar, acceder y recuperar documentos disponibles en la red.

Se percibe que la sintaxis del Núcleo de Dublín se plantea en dos vertientes: la que se puede relacionar entre el metadato básico cuya recuperación se realiza a través de los motores de búsqueda Y ahoo, Altavista, Lycos, Webcrawler y Hotbot, entre otros, y los códigos complejos de registros bibliográficos como MARC, UNIMARC y el

9 María José G imeno Montoro y otros. Catalogaaóndereursosdeetrónicosaccesiblesen Inteme: revisiónde propuestas para una namativa.

http:/ / www.florida-uni.es/ fesabid98/mj_gimeno.html 
FGD C (Federal G eographic Data Committee). No obstante se advierte que si los elementos del DC se aceptan en el marco internacional, la indización de documentos en Internet contaría con los elementos fundamentales para ello, con lo que la eficacia de los buscadores mejoraría en forma notable.

En 1998 se liberó para su revisión el borrador de norma RFC 2431 1998(4) (Re questforCommets), el que compila los resultados generados en las diversas reuniones DC y en los cambios subsecuentes. ElRFC contienelos siguientes documentos: Dublin Core Metadata for Simple Resource D escription; Encoding D ublin Core Metadata in HTML; Q ualifield D ublin Core Metadatafor Simple Resource D escription, y Encoding Qualified D ublin Core Metadata with Canberra Qualifiers. D ada la urgencia de contar con normas que tengan una amplia aceptación para la descripción de metadatos, las comunidades usuarias reales y potenciales del DC esperan ansiosamente la publicación de dichas normas.

Las características fundamentales del Núcleo de Dublín son las siguientes:

Simplicidad. Ha sido pensado tanto para que pueda ser utilizado por bibliotecarios como por cualquier autor que desee describir sus documentosy aumentar su visibilidad. Muchos de los elementos tienen una amplitud semántica casi similar a la complejidad de una tarjeta de un catálogo bibliográfico.

• Interoperabilidad Semántica. Promueve un conjunto de descriptores que permiten la unificación con otros estándares de datos, y esto incrementa la interoperabilidad semántica entre las disciplinas.

* Consenso Internacional. Tiene reconocimiento internacional con respecto al número y definición de los elementos y de recursos en web, lo quele permite desarrollar una efectiva infraestructura de búsqueda. El Núcleo de Dublín cuenta con una amplia participación y promoción en Norteamérica, Europa, Australia y Asia.

- Extensibilidad. El Núcleo de D ublín provee de una alternativa económica para la elaboración de descripciones de modelos tales como el MARC integral. Por otro lado cuenta con suficiente flexibilidad y extensibilidad como para limitar la estructura, además de una semántica muy elaborada y un amplio estándar de descripción.

¿ Flexibilidad. Nada en el D C es obligatorio, todos los elementosson opcionales y repetibles, así el usuario elige la profundidad de una descripción. 10

\section{Estructura fundamental del $\mathrm{N}$ úcleo de Dublín}

El DC consta de quince elementos, cada uno de los cuales puede expandirse de acuerdo con el uso que le dé el calificador de esquema y el de tipo. Un calificador de esquema se usa para interpretar el valor del contenido y se basa generalmente en normas externas. Un calificador de tipo determina la definición del elemento en sí mismo; los elementos poseen nombres descriptivos y su significado semántico, y cada elemento es opcional y puede repetirse y aparecer en cualquier orden.

10 Op at. Beatriz Juárez Santamaría y M. Patricia Martínez Ortega. Metadatos p.12. 
Resumiendo se puede decir que la semántica D C estructura un metaformato (formato de formatos) de catalogación y clasificación de documentos digitales. En su diseño colaboraron 52 especialistas de diversas disciplinas y actualmente participan en forma muy activa el OCLC, la Biblioteca del Congreso delos Estados Unidos y la Biblioteca Nacional Británica, entre otros organismos nacionales e internacionales.

Los elementos básicos del DC son los siguientes:

\begin{tabular}{|c|c|}
\hline Encabezado & $\begin{array}{l}\text { Se refiere al asunto o asuntos tratados en el documento electrónico, los } \\
\text { que pueden ser definidos a partir de sistemas de clasificación como } \\
\text { CDU, D D C, LCSH. }\end{array}$ \\
\hline Descripción & $\begin{array}{l}\text { D escripción textual del contenido (como resúmenes, notas relevantes, } \\
\text { etcétera) }\end{array}$ \\
\hline Título & El nombre que identifica al objeto que se requiere describir. \\
\hline Autor & La(s) persona(s) responsable(s) del contenido intelectual del objeto. \\
\hline Editor & El agente 0 agencia responsable de hacer accesible el objeto. \\
\hline Otro agente & $\begin{array}{l}\text { La(s) persona(s) como editores, traductores e ilustradores que hayan he- } \\
\text { cho una contribución intelectual significativa al contenido del trabajo. }\end{array}$ \\
\hline Fecha & Se refiere a la fecha de publicación. \\
\hline Tipo de objeto & El género del objeto como novela, poema, diccionario. \\
\hline Formato & $\begin{array}{l}\text { La manifestación física del objeto, como en PostScript, HTML, SG ML, } \\
\text { XML, archivo ejecutable en Windows. }\end{array}$ \\
\hline Identificador & Serie o número usado como identificador único del objeto. \\
\hline Relación & Ligas con otros objetos impresos o electrónicos. \\
\hline Fuente & $\begin{array}{l}\text { D ocumento original impreso o digital del cual se deriva el documento } \\
\text { digital. }\end{array}$ \\
\hline Idioma & Idioma del contenido intelectual. \\
\hline Cobertura & Localización en espacio físico y/ o duración temporal del objeto. \\
\hline $\begin{array}{l}\text { Derechos de au- } \\
\text { tor }\end{array}$ & $\begin{array}{l}\text { El contenido de este elemento se relaciona con un URL (UnifamResarce } \\
\text { Locator) o con un URI (UniformResarceIdantifies), una nota de derecho } \\
\text { de autor, un nivel de administración de derechos de autor o un servidor } \\
\text { que provea la información en forma dinámica. }\end{array}$ \\
\hline
\end{tabular}

La aplicación de los elementos mencionados con anterioridad puede ser visualizada en el ejemplo siguiente, desarrollado con base en la sintaxis del lenguaje HTML: 
Paradigmas normativos para la onganización documental en los albores del siglo... 131

REGISTRO DUBLIN CORE. DESARROLLADO EN FORMATO HTML (HyperText Markup Language)

Thoseare the DC madada induded in theament doament.

$<$ META NAME="D C.DATE.CURRENT" CONTENT="(SCHEME=ISO 31) 1997-06-11"> $<$ META NAME $=$ "DC.TITLE" CONTENT ="METADATA" $>$

$<$ META NAME="D C.TITLE.SUBTITLE" CONTENT="ELAG'97, GDANSK, JUNE 18TH $1997 ">$

$<$ META NAME ="D C.CREATOR.NAME" CONTENT="HUSBY, OLE" >

$<$ META NAME="D C.CREATOR.EMAIL" CONTENT="OLE.HUSBY@ BIBSYS.NO">

$<$ META NAME = "D C.CREATOR.AFFILIATION" CONTENT ="BIBSYS" >

$<$ META NAME $=$ "DC.SUBJECT" CONTENT="METADATA, NETWORK DOCUMENTS, DUBLIN CORE, NORDIC METADATA PROJECT">

$<$ META NAME ="DC.SUBJECT" CONTENT =" (SCHEME $=$ HUMORD $)$ KATALOGISE -

RING">

$<$ META NAME $=$ "DC.SUBJECT" CONTENT $=$ " (SCHEME $=$ HUMORD $)$ AUTOMATISK KATALOGISERING ">

<META NAME =" DC.SUBJECT" CONTENT =" (SCHEME=UDC) 681.3:02" >

<META NAME =" DC.SUBJECT" CONTENT =" (SCHEME=DDC) 005.72" >

$<$ META NAME ="DC.DESCRIPTION" CONTENT $=$ " THE ARTICLE DISCUSSES

CATALOGUING OF NETWORK DOCUMENTS AND METADATA SYSTEMS. A SPE-

CIAL TREATMENT IS GIVEN TO THE DUBLIN CORE SYSTEM, AND THE NORDIC METADATA PROJECT.">

$<$ META NAME ="DC.PUBLISHER" CONTENT="BIBSY S"

<META NAME = " DC.DATA.CREATION" CONTENT = " (SCHEME=ISO31) 199706-10" >

$<$ META NAME $=$ "D C.TYPE" CONTENT $=$ "ARTICLE" $>$

$<$ META NAME ="DC.FORMAT" CONTENT="(SCHEME=IMT) TEXT/ HTML">

$<$ META NAME =" DC.identifier.url" CONTENT = "http:/ / www.bibsys.no/ elag97/ metadata.html">

$<$ META NAME =" DC.LANGUAGE" CONTENT =" (SCHEME =NISOZ39.53) ENG" >

<META NAME=" DC.RIGHTS" CONTENT=" PUBLIC DOMAIN" >

FUENTE: Metadata ELAG'97. Http// uwwbibsysno/ dag97/ mtadatahtm

La creación de la sintaxis del Núcleo de Dublín Metadata, medio ambiente e interfaces del usuario, es o tro nivel del proyecto en el que los descubrimientos podrán generar propuestas de organización documental de consecuencias internacionales. Este nivel se refiere a los requerimientos de la sintaxis, en esta tarea el HTML formaliza la sintaxis en la que podrán ser clasificados los documentos digitales. 
Los editores del HTML se vinculan como apoyo al aprovisionamiento del DC Metadata; el software SoftQ uad es el soporte tecnológico de los editores. Una delas intenciones del DC es proveerle al autor de información digital una estructura vacía en la que pueda describir el contenido de sus documentos. Se advierte que el Núcleo de D ublín no pretende sustituir otras fuentes de descripción, más bien intenta ser un complemento de las mismas.

\section{Proyecto nórdico de metadatos $=$ Nordic Metadata Proyect}

El Proyecto Nórdico calcula su costo en 50.000 dólares y una proyección de arranque hacia 1998. Su propósito es crear mecanismos de indización y recuperar la producción documental de los países nórdicos. Los organismos participantes son los siguientes: Bibsys (Noruega), Helsinki University Library (Finlandia), Lund University Library, NetLab (Suecia), Munksgaard (D inamarca), The National and University Library of Iceland (Islandia), Swedish Institute of Computer Science (Suecia) y la D anish Library Center (D inamarca).

Los niveles básicos para el desarrollo del proyecto han sido los siguientes: evaluación de los metaformatos existentes; análisis de los elementos del formato generado por el Núcleo de Dublín; creación o conversión de formatos D C a MARC Nórdico y viceversa; creación de la sintaxis DC Metadata, medio ambiente e interfaces del usuario; aprovisionamiento, descubrimiento y recuperación de documentos nórdicos a través de Internet utilizando servicios de recuperación de metadatos; documentación y administración del proyecto.

Uno de los principales niveles de dicho proyecto se refiere a la evaluación de los formatos de metadatos con la intención de identificar el más apropiado para la descripción de documentos digitales. Algunos de los formatos analizados son: Dublin Core Metadata Elements Set, IAFA (IntemetAnonymousFTPArchive), MARC (Madine ReadableCataloging y SO IF (SummaryObeet InterdangeFomat); usado por WWW Indexing Service).

Se ha realizado un intenso trabajo con relación al software de apoyo a la indización, para ello se experimenta con las bases de datos SWEMETA y D ANAMETA, las cuales contienen 30,000 y 50.000 registros respectivamente; esos registros se encuentran en conversión a la estructura del Núcleo de Dublín.

Con base en lo anterior se puede señalar que el Proyecto Nórdico de Metadatos es un indicador que debe considerarse en la proyección de programas de esta naturaleza, pues su desarrollo ha seguido la evolución del D C y ha acumulado mucha experiencia, la que puede ser de interés para los grupos que inicien programas de esta naturaleza.

O tros desarrollos tecnológicos a considerar en la generación de sistemas de metadatos son los siguientes: 


\section{IAFA (Intemet AnonymousFTP Ardives)}

La propuesta IAFA fue liberada en 1994 y su diseño inicial se orientó a la descripción de recursos documentales accesibles en servidores FTP. Su estructura contiene la sintaxis para definir conjuntos de elementos que van a describir documentos digitales. Un par de inconvenientes son: que el conjunto de elementos es limitado parala descripción, y que no contempla las posibilidades de descripción de los diversos tipos de documentos que pueden ser accesibles a través de servidores FTP o http. El principio de la sintaxis de IAFA divide los elementos en forma y contenido de la siguiente manera:

\begin{tabular}{|l|l|}
\hline Nombre del elemento & Contenido del elemento \\
\hline Autor & LAFUENTE LÓ PEZ, Ramiro \\
\hline Título & Biblioteca digital y orden documental \\
\hline
\end{tabular}

D escribir recursos digitales de esta manera puede ser relativamente sencillo, sin embargo se debe tener presente que hasta el momento los desarrollos para esta tarea utilizando IAA han sido realizados por diseñadores de sintaxis, quienes han determinado las características y el número de elementos que serán utilizados en la descripción de recursos informativos digitales. En consecuencia si lo que se persigue es normalizar recursos de esa naturaleza utilizando IAFA, los diseñadores deberán incluir la participación del sector bibliotecario en la construcción de la sintaxis apropiada, y por tanto tomar en cuenta las necesidades de usuarios específicos y las posibilidades de uso que pueda tener la información.

La caracterización descriptiva deIAFA puede ser equivalente a etiquetas y contenido en los formatos bibliográficos; sin embargo, cabe notar que dichos formatos contienen en su estructura diversas posibilidades para describir recursos informativos a niveles de microrrelaciones, aspecto que puede ser relevante en la recuperación de información, lo cual no se percibe en IAFA.

En la implementación de IAFA se ha realizado una labor importante en cuanto a desarrollo de software, aspecto que les ha sido atractivo a diversos organismos y a sectores interesados en la organización documental. Algunas aplicaciones del mismo han sido realizadas por las instituciones siguientes:

a) Programa de indización ISITE del CNID R (Center for Networked Information D iscovery and Retrieval); el paquete de programas que utiliza está integrado por un manejador de bases de datos y protocolos de comunicación Z39.50, http y FTP.

b) La Biblioteca del Congreso de los Estados Unidos utiliza IAFA para construir pasarelas Web hacia bases de datos bibliográficos de bibliotecas que utilizan dicho protocolo. 
Cabe advertir que si se pretendelograr una normalización en la descripción de recursos digitales a través del uso de IAFA, se requerirá de un intenso trabajo de grupos interdisciplinarios que tomen en cuenta las necesidades de la organización documental específicas de las unidades de información implicadas, y el uso local, nacional e internacional de los documentos digitales que se pretenda organizar. Sin embargo, los logros del trabajo realizado por los organismos mencionados pueden ser de mucha utilidad para los grupos interdisciplinarios que deban abordar tareas de esta naturaleza.

Un ejemplo de esto es el trabajo que realiza la OMNI (O rganising Medical Networked Information) utilizando la plataforma IAFA (Internet Anonymous FTP Archive), como se muestra a continuación.

\begin{tabular}{|c|c|c|}
\hline \multicolumn{3}{|c|}{ REGIST RO IAFA. O MNI (O rganising Medical Networked Information) } \\
\hline \multicolumn{3}{|c|}{ IAFA Template (Intemet Anonymous FTP Archive) } \\
\hline Template-Type: & \multicolumn{2}{|c|}{ DOCUMENT } \\
\hline Handle: & \multicolumn{2}{|c|}{$83381296-7713$} \\
\hline Title: & \multicolumn{2}{|c|}{ Better care of the child with cancer } \\
\hline URI-v1: & \multicolumn{2}{|c|}{ http:/ / www.dundee.ac.uk/ MedE d/ webupdate/ child/ cancer.htm } \\
\hline URI-v2: & \multicolumn{2}{|c|}{ http:/ / www.dundee.ac.uk/ MedE d/ webupdate/ child/ cancer.htm } \\
\hline Author-Name-v1: & \multicolumn{2}{|c|}{ Richard Stevens MRCP MRCPath } \\
\hline Author-Job-Title-v1: & \multicolumn{2}{|c|}{ Consultant Oncologist } \\
\hline Admin-E mail-v1: & \multicolumn{2}{|c|}{ update@ dundee.ac.uk } \\
\hline D escription: & \multicolumn{2}{|c|}{$\begin{array}{l}\text { An article on childhood cancers from Web Update, covering a } \\
\text { summary of the various types of malignancy, etiology, } \\
\text { improvements in survival rates in recent years. }\end{array}$} \\
\hline \multicolumn{3}{|c|}{ Publisher-Name-v1: Centre for Medical Education, University of D undee } \\
\hline \multicolumn{3}{|c|}{ Subject-D escriptor-v1: $\quad 616-006$} \\
\hline \multicolumn{2}{|c|}{ Subject-D escriptor-v2: } & QZ275 \\
\hline \multicolumn{2}{|c|}{ Subject-D escriptor-Scheme-v1: } & UDC \\
\hline \multicolumn{2}{|c|}{ Subject-D escriptor-Scheme-V2: } & NLM \\
\hline \multicolumn{2}{|l|}{ To-Be-Reviewed-D ate: } & 960901 \\
\hline D estination: & & omniuk \\
\hline \multicolumn{2}{|c|}{ Record-Last-Modified-D ate: } & Tue, 03 Jun 1996 14:49:55+0000 \\
\hline \multicolumn{2}{|c|}{ Record-Last-Modified-Email: } & unknown@mail-address \\
\hline \multicolumn{2}{|l|}{ Record-Created-D ate: } & Tue, 03 Jun 1996 14:42:44+0000 \\
\hline \multicolumn{2}{|c|}{ Record-Created-Email: } & unknown@mail-address \\
\hline
\end{tabular}


Paradigmas normativos para la organización documental en los albores del siglo... 135

* PICS (Platformfor Inteme Content Seletion)=Plataforma para Seleccionar Contenidos en Internet

El desarrollo de esta plataforma se ha orientado a considerar la elaboración de mecanismos tecnológicos que faciliten la clasificación de sitios web, lo cual permite hacer ligas de recursos digitales disponibles en Internet. Este aspecto determinauna orientación de metadatos, contempla códigos de reconocimiento, confidencialidad y propiedad intelectual, y hace factibleclasificar el contenido de páginas web tomando en consideración sus objetivos y sus valores.

En el desarrollo de PICS se consideraron, entre otras variables, las diversas posibilidades que tienen los contenidos en Internet. En la actualidad, las investigaciones en torno a los diversos aspectos tecnológicos de PICS y de los contenidos de los recursos digitales en Internet están a cargo del W3C (WorldWideWebConsartium) y de sus grupos de trabajo, como PICS-NG (NextGeneation), el cual se ocupa de describir recursos digitales, y el grupo W3C RDF (ResarceDesciption Framenak=Marco de D escripción de Recursos) del desarrollo de aplicaciones adicionales.

La intención fundamental del RD F11 es crear un modelo que soporte metadatos en Web, que esté fundamentado en las estructuras del Núcleo de Dublín, Warwick Framework y en el lenguaje XML (eXtensibleMarkupLanguag). En consecuencia el $\mathrm{RDF}$ se perfila como un paradigma que contempla la clasificación, el intercambio y la reutilización de metadatos estructurados con base en diversos formatos de descripción de recursos digitales como D C, PICS eIAFA. Esto se pretenderealizar a tra vés de la introducción de un modelo de descripción para representar metadatos, y una sintaxis para expresarlos y transferirlos, todo con el fin de maximizar la interoperabilidad entre servidores web.

El RD F determina la descripción de recursos digitales como objetos identificables por un Uniform Resource Identifier (URI) a través de propiedades tipo y de los valores característicos de un recurso documental. Con base en un modelo que contemple la propiedad-tipo-valor del documento, el RDF intenta generar un método semántico que no sea ambiguo para facilitar su interpretación por computadoras. En este sentido elRD F le proporciona al XML el modelo formal para darle soporte a la representación consistente de la semántica; así el lenguaje XML orienta la estructura del templete RD F a través de una semántica normalizada que determina la objetivación de la clasificación documental digital y facilita el procesamiento de metadatos en forma consistente.

Se advierte que las aplicaciones potenciales deRDF son múltiples, los metadatos en este entorno pueden aplicarse a una gran variedad de áreas: la descripción y clasificación de recursos digitales; la búsqueda y recuperación documental; la localización de

11 La descripción de RDF se basó en: Resorce Description Framework (RDF) Model and Syntaxis Specification: W3C Working D raft 080 ctober 1998, y Gimeno Montoro, María José, y otros. Ca talogacón dereaursos dectrónicos accesibles en Intene: revisón depropuestas para una nomativa.

http:/ / www.florida-uni.es/ fesabid98/ mj_gimeno.html 
hipervínculos de contenido temático de información disponible en sitios web o en bibliotecas digitales; la descripción de colecciones en páginas web; la identificación de derechos de propiedad intelectual en web, etcétera.

\section{EN CONCLUSIÓN}

Los hechos indican que el paradigma creado con la aparición de formatos bibliográficos tiene como intención principal ofrecer un conjunto deelementos para describir documentos y facilitar su intercambio e interpretación a través decomputadora. El modelo propuesto por los formatos digitales tiene como propósito estructurar una sintaxis que facilite la definición de un conjunto de elementos (como es el caso delDC basado en HTML) con el fin de incorporar a los sistemas de metadatos la representación de información digital.

En consecuencia el reconocimiento por parte de los bibliotecarios de las diferencias entre catalogar registros bibliográficos y procesar información digital para estructurar sistemas de metadatos y bibliotecas digitales, es un requisito fundamental para reorientar las tareas bibliotecarias que requieren los modelos creados por las tecnologías de información, los cuales están sujetos a cambios constantes que afectan las actividades que requierela sistematización documental y cuyo propósito debe seguir siendo facilitar la recuperación y el uso de la información para las sociedades.

Es evidente que la selección y la descripción normativa de recursos electrónicos disponibles en Internet se hace cada vez más urgente debido a los aspectos siguientes: crecimiento exponencial de la información en línea; existencia de una tipología documental múltiple; einestabilidad debidaa continuas actualizaciones dada su disponibilidad temporal y el requerimiento de fiabilidad. A lo anterior habría que agregar los desarrollos en formatos digitales como SG ML, HTML, XLM, el desarrollo constante de software para la gestión de información y los avances alcanzados en protocolos de comunicación como Z39.50, X500 y en los sistemas O SI (Open Sistems Inteconnetion).

Por tanto se advierte que las tareas sustantivas de los bibliotecarios en los albores del siglo XXI se orientarán hacia los desarrollos tecnológicos mencionados en el pá rrafo anterior: Sin embargo la selección apropiada del formato digital, la reorientación o generación de la normalización necesaria para representar recursos documentales en sistemas de metadatos, las bibliotecas digitales y el software de gestión, se perfilan como tareas urgentes paralos sectores bibliotecarios. Pero también serán tareas importantes para dichos sectores el desarrollo de nuevas habilidades, la apropiación de nuevos desarrollos tecnológicos y la proyección de escenarios sociales en los que incida el trabajo referido a la organización de documentos digitales.

LaWorld Wide Web puede facilitar el acceso múltiple a sistemas de información distribuida pero requiere de mucha más investigación multidisciplinaria dirigida a la organización de recursos digitales, aspecto que puede propiciar el desarrollo de 
investigaciones colectivas que se propongan crear, desarrollar y normalizar los instrumentos necesarios que permitan su implementación apropiada en el almacenamiento, la búsqueday la recuperación de lainformación disponible en redes. En este sentido, se advierte que la investigación dirigida a la creación de sistemas metadatos y bibliotecas digitales será prioritaria en los inicios del siglo XXI.

Asimismo se percibe que lainvestigación dirigida al modelo RD F (Resource D escription Framework) se propone facilitar la localización de información y potenciar la eficacia de los motores de búsqueda por lo que toca a la relevancia en la recuperación de documentos. En consecuencia se debe comprender, de manera cabal, que la teoría que subyace en los sistemas de metadatos indica que hay que tomar en cuenta las características y la relación que puede haber entre los elementos descriptivos de documentos en general y los elementos de representación de información digital. Lo anterior ha inducido una línea de investigación que aborda el tratamiento de los documentos como objetos (DLO. DoumentLikeObjets).

Los registros catalográficos tal como los han producido tradicionalmente los bibliotecarios son bastante genéricos en el sentido de que hacen pocas suposiciones sobre los usuarios potenciales de estos registros. El contexto futuro de uso (integración en un OPAC o colocación de las fichas impresas en un catálogo organizado de manera secuencial) ha tenido hasta ahora muy poco impacto en la manera en que esta información se creaen el proceso de catalogación y no ha influenciado demasiado la semántica (tal como está formalizada en los códigos decatalogación tipo AACR2). Este hecho puede ser una ventaja, sin embargo, la comunidad bibliotecaria es actualmente mucho más consciente de las desventajas de esta falta de orientación hacia el usuario final de la actividad catalográfica y está obligada a reconsiderar algunos de sus principios. ${ }^{12}$

En este contexto se advierte que las características del DC y de los proyectos de metadatos se han propuesto tomar muy en cuenta los requerimientos de los usuarios finales de la información, en consecuencia se analiza el valor que tiene la simplicidad para describir recursos digitales frente a la complejidad descriptiva que puede requerir la descripción de metadatos estructurados.

Lo anterior tiene sentido si se piensa en la descripción de los elementos fundamentales de la información digital con el propósito de que su sistematización esté acorde con los requerimientos de los sujetos que la utilizarán con distintos propósitos: autores, editores, estudiantes, profesores, investigadores y bibliotecarios. Es conveniente insistir en que los bibliotecarios tienen el reto de buscar o adecuar las herramientas normativas que garanticen la organización normalizada de recursos digitales, y en que el usuario final de la información no encuentre barreras normativas que le impidan obtener la información apropiada a sus requerimientos. También es conveniente tomar en consideración que uno de los objetivos de los nuevos

12 Stefan G radmann. “Catalogación versus metadata: ¿Vino viejo en odres nuevos?”. En IFLA G eneral Conference (64 :1998). http:/ / ifla.inist.fr/ IV/ ifla64/ 007-126s.html 
desarrollos tecnológicos está orientado al diseño de herramientas versátiles y cada vez de más fácil utilización por parte de cualquier ciudadano.

El hecho de buscar calidad y contenido en la organización de recursos digitales en beneficio de los usuarios finales de la información, pone de manifiesto la oportunidad que tienen los sectores bibliotecarios para ayudar al usuario final al facilitarle el acceso y uso de los recursos digitales apropiados para satisfacer sus requerimientos informativos, y asegurarle continuidad y consistencia en la sistematización de los mismos. En este sentido al analizarse las repercusiones que plantea el tratamiento de documentos como objetos en laWWW, y la orientación que requiere la búsqueda de precisión que se reclama de los buscadores de información en Internet, se deben tener muy presente los aspectos siguientes:

Los metadatos son parte de una infraestructura de información técnica concreta, y esto es así, incluso hasta cierto punto en el nivel semántico, ya que en principio estaban pensados para ser independientes del contexto: el valor real del registro de metadatos viene determinado en gran medida por el hecho de que los punteros de acceso del registro funcionen realmente, lo cual explica la gran preocupación mostrada en las discusiones del D C sobre el problema de las "conexiones rotas" y su relación con los procesos de estandarización relacionados con el URN (u otro identificador) y también por el hecho de que los punteros de acceso cumplan los requisitos técnicos del software utilizado para acceder a la información. Si este aspecto se simplifica mucho, se podría decir que un registro de me tadatos que contenga un puntero inválido del recurso vale casi tan poco como la ausencia del registro.

Los metadatos no sólo pertenecen a un paradigma de producción diferente, sino que también pretenden ser parte de un contexto de uso distinto de los registros catalográficos y que está técnicamente conectado a este contexto en alto grado. Si bien esta afirmación parece simplificar enormemente las cosas (permitiendo el acceso directo al documento a partir de métodos normalizados de punteros), paradójicamente las cosas se complican al mismo tiempo. El papel de los registros de metadatos en estainfraestructura de información depende de la evolución constante de los estándares orientados a Internet los cuales cambian y evolucionan constantemente..$^{13}$

Es claro que la catalogación-codificación de registros bibliográficos y la descripción de recursos digitales determinan dos enfoques distintos que se orientan principalmente a partir de las particularidades de las infraestructuras tecnológicas y de información a las que pertenecen. Un ejemplo son algunos proyectos que utilizan catálogos en línea(OPAC's) como pasarelas deacceso ainfraestructuras de metadatos. La riqueza de este enfoque consiste en que, en su momento, ambas infraestructuras puedan ser complementarias en beneficio de los usuarios finales de la información.

\section{Ibidam}


Sin embargo, mantener consistencia en la descripción de metadatos de contenido puede ser un requisito para su mayor aprovechamiento, en este sentido, los campos de autenticidad, resumen, y temas, como llaves de recuperación, se perfilan como determinantes en la producción de metadatos. Por esta razón los bibliotecólogos y los especialistas en lenguaje documental tendrán retos desafiantes debido a lo fundamental del mismo en el acceso y la recuperación de la información. En consecuencia, la consistencia que se logre en este campo será determinante para estas tareas.

Por lo que se refiere a la consistencia para producir metadatos, los sectores de bibliotecarios pueden contribuir de manera determinante dada la experiencia mostrada a través de las épocas en la organización documental. Sin embargo, debe entenderse cabalmente que no se trata de realizar sistemas de metadatos que solo impliquen una actividad de transferencia, como se hizo en diversos proyectos iniciados con la aparición de la computadora, que solo transportaron el catálogo en tarjetas a un medio computacional y desaprovecharon diversas posibilidades de cómputo.

Ladescripción de metadatos requiere que se tomen en consideración los siguientes elementos: identificación descriptiva; citas relacionadas con la descripción; periodo de tiempo; calidad e integridad de la información; entidades y atributos; formatos digitales para su intercambio y distribución, y referencias a metadatos afines. Es indispensable que los bibliotecarios conozcan y apliquen la normalización internacional apropiada a la descripción de metadatos, desarrollen habilidades referidas a la apropiación de tecnologías de información y trabajen la capacidad cognoscitiva para identificar, valorar, analizar e interpretar lainformación que requiere la descripción de metadatos tomando en consideración las necesidades de información de los sujetos sociales según los escenarios en los que se encuentren insertos.

A este respecto, Stuart Weibel ha señalado lo siguiente:

[...]los metadatos son como tallos del paradigma de la información que difieren de otros que representan la actividad de la catalogación bibliotecaria y creo que las bibliotecas deberían sentirse invitadas a seguir intensamente su evolución y a no percibirlos como una amenaza, sino como una oportunidad de redefinir su papel en el contexto de los paradigmas de información emergentes. ${ }^{14}$

14 Stuart Weibel. "A uthentication of Metadata.meta2". Citado por Stefan G radmann. "Catalogación versus metadata:.. ¿Vino viejo en odres nuevos?". En IFLA Geneal Conferene(64 : 1998) http:/ / ifla.inist.fr/ IV/ ifla64/ 007-126s.html. 


\section{BIBLIOGRAFÍA}

Amett, Nick. Authentication fmmtadata Meta2@ mrrl.lut.ac.uk (23 Jan. 1998)

Barker, Phillip G. "Electronic libraries : vision of the future". En TheEletronicLibranies(12):221-230, august 1994.

Berners-Lee, Tim. MatadataArditecture Douments, Mtadata, and Links Last edit date: 1998/ 02/ 06.

http:/ / www.w3.org/ D esignIssues/ Metadata.html

Browning, J. "Libraries without walls for books without pages". En Wired1(1): 6-8, 1993.

Caplan, Priscilla. "Y ou call it comer, we call it syntax-independet metadatafor 'D ocument like objet'." Citada por Rachel Heery. "Review of metadata formats". En Program automateellibraryand infomation systems 30(4):346, oct. 1996.

- - - . "Y ou Call It Con, We Call It Syntax-Independent Metadata for D ocuments-Like Objects". En ThePublicA cess Computer Systems Review 6(4) (1995).

http:/ / info.lib.uh.edu/ pr/ v6/ n4/ cap16n4.html

D ovey, Matthew J. "Stuff" about "Stuff" the differing meanings of "metadata". En Vine, Mtadata, part 1, num.16 p.6-13, 1999.

The Dublin Core Initiative.

http:/ / purl.oclc.org/ metadata/ D ublin core/

The $4^{\text {th }}$ D ublin Core Metadata Workshop Report : D C-4 / Stuart Weibel; Renato Iannella; Warwick Cathro, National Library of Australia, 1997.

http:/ / www.dlib.org/ dlib/ june97/ metadata/ 06weibel.html

Enrech, M. "La gestió del documentelectrònic: I'experiència de la Biblioteca dela UOC. \& es". En JomadesCatalanesdeDcamentadón/ D. Maniega, J., Serrano, N. Comellas. Barcelona: Socadi, Cobdc, 1997. p.115-129.

Gimeno Montoro, María Joséy otros. Catalogadónderearsosdetró nicosaccesibles en Intent: revisión depropuestas para una nomativa. http:/ / www.florida-uni.es/ fesabid98/ mj_gimeno.html

Gradmann, Stefan. "Catalogación versus metadata:.. ¿Vino viejo en odres nuevos?". En IFLA Geneal Conferenee(64 : 1998 : Copenhague, D inamarca).

http:/ / ifla.inist.fr/ IV/ ifla64/ 007-126s.html.

Heery, Rachel. "Review of metadata formats". En Progam auto matedlibraryandinformation systems 30(4):346, oct. 1996. 
Hudgins, Jean. Gettingmileageat of mtadata: applications for thelibrary/ G race Agnew y Elizabeth Brown. United States of America: American Library Association, 1999. 80 p. (Lita Guides; 5)

Inteme, madadtosyaccesoalainformacónenbiblidecasyreedesenlaea detrónical Filiberto Felipe Martínez Arellano, Lina Escalona Ríos, comp.; tr. de documentos en inglés Filiberto F. Martínez Arellano. México: UNAM, CUIB; Infoconsultores, 2000. 112 p. : il. (Sistematización dela Información D ocumental ; 1)

Juárez Santamaría, Beatriz y M. Patricia Martínez O rtega. Matadatos México : UNAM, Facultad de Filosofía y Letras, Posgrado en Bibliotecología, 1999. p.8. (Trabajo presentado en el Seminario sobre Normalización dela Información Documental)

Kuny, Terry and Gary Cleveland. "The digital library : myths and challenges". En IFLA Jaumal 24(2):107-113, march. 1998.

Lassila, Ora. Introduction to RDF madada W3C note 1997-11-13. http:/ / www.w3.org/ TR/ NOTE-RDF simple-intro-971113.html

- - -. PICS-NG madadta modd andlabd syntax. W3C note 1997-05-14. http:/ / WWW.w3.org/ TR/ NOTE-PICS-NG-METADATA

Metadata. ELAG'97. G dansk, june 18 1997. http:/ / www.bibsys.nolelag97/ metadata.html

Miller, Eric. Anintrodurtiontotheresarcedesciptionframenork.D-Lib Magazine. 1998.

http:/ / www.dlib.org/ dlib/ may98/ miller/ 05miller.html

Miller, Paul. "Metadata for the Masses”. En Ariadne 5 (Sept. 1996). http:/ / www.ariadne.ac.uk/ issue5/ metadata/ -masses/

Morales Campos, Estela, coord. Labiblictecadd futura México : UNAM, D irección General de Bibliotecas, 1996. 336 p.

ResaurceDesciptionFramevork (RDF) schemas W3C working D raft 9 april 1998. Edited by D an Brickley, R. V. Guha, Andrew Layman. http:/ / www.w3.org/ TR71998/ wD-rdf-schema-19998880409

Serra i Serra, Jordi. "Archivar Internet". En El proesional dela infomaaón (7):14-18, jul.-ago. 1998.

StatementontheintettanduseofPICS: usingPICSwdl W3C note 1 june-1998. Edited by Joseph Reagle, D aniel J. Weitzner. http/ / www.ww3.org/ TR/ NOTE-PICS-Statement

Steel, Warren. [en línea] "Trucos para nuevos autores". http:/ / wwwm csr.olemiss.edu/ mudws/ webhints.html. En HTML 4.0/ E. Stephen Mack y Janan Platt. Madrid : Anaya Multimedia, 1998. p.51.

A UsaGuidefor SimpleDublin Care D raft version 4.0. (15/ 05/ 1998) http:/ / www.128.253.70.110/ UserG uide4.html (USER GUIDE)

Weibel, Stuart. "Authentication of Metadata.meta2". Citado por Stefan Gradmann. "Catalogación versus metadata:.. ¿Vino viejo en odres nue- 
vos?”. En IFLA General Conference(64 : 1998 : Copenhague, Dinamarca)

http:/ / ifla.inist.fr/ IV/ ifla64/ 007-126s.html

Weibel, Stuart y Juha Hakala. DC-5: theHdsinki mtadata workshop A report ontheworkshqpandsubsequent derelopments D-LibMagezine (February 1998).

http:/ / www.dlib.org/ dlib/ february98/ 02wibel.html

$\mathrm{Xu}$, Amanda. "Metadata Conversion and the Library O PAC". En

TheSeialsLibraian, 33 (Spring 1998).

http:/ / web.mit.edu/ waynej/ www/ xu.htm

\section{A NEXO 1.}

T abla comparativa de los campos del $N$ úcleo de Dublín, HTML y etiquetas MARC 21

\begin{tabular}{|c|c|c|}
\hline DUBLIN CORE & HTML & MARC 21 \\
\hline $\begin{array}{l}\text { Encabezado. Se refiere al } \\
\text { asunto o asuntos (temas) trata- } \\
\text { dos en el documento electróni- } \\
\text { co, los que pueden ser } \\
\text { definidos a partir de sistemas } \\
\text { de clasificación como CD U, } \\
\text { DDC, LCSH. }\end{array}$ & $\begin{array}{l}<\text { META NAME }= \\
\text { "DC.SUBJECT" CON- } \\
\text { TENT }=\text { " "> }\end{array}$ & $\begin{array}{l}\text { 050\#\# \$a Clasificación LC } \\
\text { 082\#\# \$a Clasificación D ecimal D ewey } \\
653 \# \text { \$a término no controlado } \\
650 \# \# \text { \$a, \$2 códigos fuente USMARC } \\
650 \# \# \text { \$a Encabezamiento, esquema } \\
\text { LCSH. } \\
\text { 655\#\# \$a término del índice, con códi- } \\
\text { go de subcampo \$2=término local. }\end{array}$ \\
\hline $\begin{array}{l}\text { Descripción. Descripción tex- } \\
\text { tual del contenido (como resú- } \\
\text { menes, notas relevantes, } \\
\text { etcétera) }\end{array}$ & $\begin{array}{l}<\text { META NAME } \\
\text { "DC.DESCRIPTION" } \\
\text { CONTENT }=" \text { " > }\end{array}$ & $\begin{array}{l}\text { 500\#\# \$a nota general } \\
513 \# \# \text { \$a, \$b nota de reporte } \\
\text { 520\#\# \$a nota de resumen } \\
522 \# \# \text { \$a nota de cobertura geográfica }\end{array}$ \\
\hline $\begin{array}{l}\text { Título. El nombre que identifi- } \\
\text { ca al objeto que se requiere } \\
\text { describir. }\end{array}$ & $\begin{array}{l}<\text { META } \\
\text { NAME }=\text { "D C.TITLE" } \\
\text { CONTENT }=" \text { "> }\end{array}$ & $24500 \$ a$ título \\
\hline
\end{tabular}




\begin{tabular}{|c|c|c|}
\hline DUBLIN CORE & HTML & MARC 21 \\
\hline $\begin{array}{l}\text { Autor. La(s) persona(s) respon- } \\
\text { sable(s) del contenido intelec- } \\
\text { tual del objeto. }\end{array}$ & $\begin{array}{l}<\text { META NAME = } \\
\text { "DC.CREATOR" } \\
\text { CONTENT =" "> } \\
<\text { META } \\
\text { NAME ="AC.Email"• } \\
\text { CONTENT=" "> }\end{array}$ & $\begin{array}{l}\text { 10000\$a autor personal } \\
11000 \$ a \text { autor corporativo }\end{array}$ \\
\hline $\begin{array}{l}\text { E ditor. El agente o agencia } \\
\text { responsable de hacer accesible } \\
\text { el objeto. }\end{array}$ & $\begin{array}{l}<\text { META } \\
\text { NAME ="DC.PU- } \\
\text { BLISHER" CON- } \\
\text { TENT }=" \text { "> }\end{array}$ & $\begin{array}{l}\text { 260\#\# \$a, \$b publicación, distribución, } \\
\text { nombre del editor, etc. }\end{array}$ \\
\hline $\begin{array}{l}\text { Otro agente. La(s) persona(s) } \\
\text { como editores, traductores e } \\
\text { ilustradores que hayan hecho } \\
\text { una contribución intelectual } \\
\text { significativa al contenido del } \\
\text { trabajo. }\end{array}$ & $\begin{array}{l}<\text { META NAME }= \\
\text { "DC.CONTRIBUTOR" } \\
\text { CONTENT }=" \text { "> }\end{array}$ & $\begin{array}{l}7001 \# \text { \$a (nombre personal) \$e función } \\
7102 \# \text { \$a (nombre corporación) \$e fun- } \\
\text { ción } \\
7112 \# \$ a \text { (nombre reunión) \$e función } \\
720 \# \# \text { \$a, nombre no controlado \$e } \\
\text { función. } \\
7760 \# \$ a \text {, \$u otro identificador } \\
7730 \# \$ a \text { a, \$n ítem anfitrión } \\
7740 \# \sim \text { \$a, \$0 entrada componente de } \\
\text { la unidad } \\
7870 \# \$ n \text { relación no especificada } \\
787 \# \# \text { \$0 relación no especificada, es- } \\
\text { quema URL. }\end{array}$ \\
\hline $\begin{array}{l}\text { Fecha. Se refiere a la fecha de } \\
\text { publicación. }\end{array}$ & $\begin{array}{l}<\text { META NAME }= \\
\text { "DC.DATE" CON- } \\
\text { TENT }=\text { " "> }\end{array}$ & $\begin{array}{l}\text { 260\#\#, \$a, \$c fecha de publicación } \\
005 \text { fecha y hora de la modificación } \\
\text { MARC-ISO 8611: } 008 \text { posición (7-10) }\end{array}$ \\
\hline $\begin{array}{l}\text { Tipo objeto. El género del ob- } \\
\text { jeto como novela, poema, dic- } \\
\text { cionario. }\end{array}$ & $\begin{array}{l}<\text { META NAME }= \\
\text { "DC.TYPE" CON- } \\
\text { TENT =" "> }\end{array}$ & $\begin{array}{l}\text { Naturaleza del contenido, 008, posicio- } \\
\text { nes } 24-27\end{array}$ \\
\hline $\begin{array}{l}\text { Formato. La manifestación fí- } \\
\text { sica del objeto, como en } \\
\text { PostScript, HTML, SG ML, XML, } \\
\text { archivo ejecutable en Windows }\end{array}$ & $\begin{array}{l}<\text { META NAME }= \\
\text { "DC.FORMAT" CON- } \\
\text { TENT }=" \text { " }\end{array}$ & $\begin{array}{l}\text { 300\#\# \$a descripción física } \\
\text { 340\#\#\$a medio físico } \\
\text { 856(1er indicador \#, } 0 \text { correo electróni- } \\
\text { co, } 1 \mathrm{FTP}, 2 \text { Conexión remota, } 3 \mathrm{D} \text { ial } \\
\text { up, } 4 \text { http, 20 indicador \#, } 0 \text { fuente, } 1 \\
\text { versión, } 2 \text { recurso electrónico) \$a, \$q } \\
\text { localización electrónica y acceso. }\end{array}$ \\
\hline
\end{tabular}




\begin{tabular}{|c|c|c|}
\hline DUBLIN CORE & HTML & MARC 21 \\
\hline $\begin{array}{l}\text { Identificador. Serie o número } \\
\text { usado como identificador único } \\
\text { del objeto. }\end{array}$ & $\begin{array}{l}<\text { META NAME }= \\
\text { "DC.IDENTIFIER" } \\
\text { CONTENT }=\text { " "> }\end{array}$ & $\begin{array}{l}020 \# \# \$ a \text { ISBN } \\
022 \# \# \$ a \text { ISSN }\end{array}$ \\
\hline $\begin{array}{l}\text { Relación. Ligas con otros ob- } \\
\text { jetos impresos o electrónicos. }\end{array}$ & $\begin{array}{l}<\text { META NAME = } \\
\text { "DC.RELATION" } \\
\text { CONTENT }=" \text { "> }\end{array}$ & $\begin{array}{l}\text { 856\#\# \$a, \$u Identificador electrónico } \\
\text { 856\#\#, \$a, \$q localización electrónica } \\
\text { y acceso. } \\
\text { 856\#\#\$a, \$b Identificador tipo } \\
\text { 8567\#\$a, \$u URN } \\
\text { 0248\#\$a (O tro identificador estándar). }\end{array}$ \\
\hline $\begin{array}{l}\text { Fuente. D ocumento original } \\
\text { impreso o digital del cual se de- } \\
\text { riva el documento digital. }\end{array}$ & $\begin{array}{l}<\text { META NAME }= \\
\text { "DC.SO URCE" CON- } \\
\text { TENT=" "> }\end{array}$ & $7860 \# \$ \mathrm{a}$, $\$ \mathrm{n}$ datos de la fuente \\
\hline $\begin{array}{l}\text { Idioma. Idioma del contenido } \\
\text { intelectual. }\end{array}$ & $\begin{array}{l}<\text { META NAME }= \\
\text { "DC.LANGUAGE" } \\
\text { CONTENT =" "> }\end{array}$ & $\begin{array}{l}\text { 546\#\# \$a Nota de idioma } \\
\text { 041\#\# \$a código de idioma, esquema } \\
\text { USMARC, Z39.53 }\end{array}$ \\
\hline $\begin{array}{l}\text { Cobertura. Localización en es- } \\
\text { pacio físico y/ o duración tem- } \\
\text { poral del objeto. }\end{array}$ & $\begin{array}{l}<\text { META NAME }= \\
\text { "DC.COVERAGE" } \\
\text { CONTENT }=" “>\end{array}$ & $\begin{array}{l}255 \# \# \text { \$a, \$c dato cartográfico } \\
500 \# \# \text { \$a nota general } \\
513 \$ \text { b nota temporal } \\
\end{array}$ \\
\hline $\begin{array}{l}\text { Derechos de autor. El conte- } \\
\text { nido de este elemento se rela- } \\
\text { ciona con un URL (Uniform } \\
\text { Resource Locator) o con un } \\
\text { URI (Uniform Resource Identi- } \\
\text { fiers), una nota de derecho de } \\
\text { autor, un nivel de administra- } \\
\text { ción de derechos de autor o un } \\
\text { servidor que provea la informa- } \\
\text { ción en forma dinámica. }\end{array}$ & $\begin{array}{l}<\text { META NAME }= \\
\text { "DC.RIGHTS" CON- } \\
\text { TENT }=\text { " “> }\end{array}$ & $\begin{array}{l}856 \# \# \$ \mathrm{a} \text {, } \$ \mathrm{u} \text { URL, con código } \$ 3=\mathrm{de}- \\
\text { rechos de autor. }\end{array}$ \\
\hline
\end{tabular}

- IAC. Etiqueta de expansión en HTML, no definida en los15 elementos del $\mathrm{Du}$ blin Core 
ANEXO 2

A Igunos proyectos y sistemas que utilizan o tienen proyectado el uso de la estructura del $\mathrm{N}$ úcleo de Dublín

\begin{tabular}{|c|c|c|}
\hline PAís & PROYECTO & DIRECCIÓN \\
\hline \multirow{14}{*}{$\begin{array}{l}\text { América } \\
\text { del } \\
\text { Norte }\end{array}$} & $\begin{array}{l}\text { Berkeley Digital Library SunSi- } \\
\text { te }\end{array}$ & http:/ / sunsite.berkley.edu./ InternetIndex \\
\hline & $\begin{array}{l}\text { Biblioteca D igital de la Univer- } \\
\text { sidad Internacional de Florida }\end{array}$ & http:/ / www.fiu.edu/ diglib/ \\
\hline & $\begin{array}{l}\text { Biblioteca Digital de la Univer- } \\
\text { sidad de Washington }\end{array}$ & http:/ / content.engr.washington.edu/ \\
\hline & $\begin{array}{l}\text { Biblioteca D igital y registro de } \\
\text { Bases de D atos de la Universi- } \\
\text { dad de Michigan }\end{array}$ & http:/ / www.lib.mich.edu/ registry/ \\
\hline & $\begin{array}{l}\text { Biblioteca Electrónica de Mon- } \\
\text { ticello }\end{array}$ & http:/ / www.solinet.net/ monticello/ \\
\hline & $\begin{array}{l}\text { Canadian Library Web Sites } \\
\text { and Catalogues by Región }\end{array}$ & http:/ / www.nlc-bnc.ca/ canlib/ eindex.htm \\
\hline & Catálogo y Biblioteca Digital & http:/ / sunsite.berkeley.edu/ Catalog \\
\hline & $\begin{array}{l}\text { CORC (Catálogo Cooperativo } \\
\text { de recursos en línea) }\end{array}$ & $\begin{array}{l}\text { http:/ / www.oclc. O rg/ oclc/ research/ } \\
\text { projects/ corc/ index.htm }\end{array}$ \\
\hline & Digital Libraries Project & http:/ / scholar.lib.vt.edu/ digilib/ \\
\hline & $\begin{array}{l}\text { Entrada para la Educación de } \\
\text { Materiales }\end{array}$ & http:/ / gem.syr.edu \\
\hline & Mantis & http:/ / purl.oclc.org/ mantis \\
\hline & $\begin{array}{l}\text { Miami-D ade Community Colle- } \\
\text { ge (Digital Library) }\end{array}$ & http:/ / www.mdcc.edu/ digilib/ \\
\hline & $\begin{array}{l}\text { The O hio State University Li- } \\
\text { braries }\end{array}$ & http:/ / www.lib.ohio-state.edu/ catalogs.html \\
\hline & Proyecto Médico de Metadatos & $\begin{array}{c}\text { Http:/ / medir.ohsu.edu/ maletg/ } \\
\text { MedMetadata.HTM }\end{array}$ \\
\hline
\end{tabular}




\begin{tabular}{|c|c|c|}
\hline PAís & PROYECTO & DIRECCIÓN \\
\hline \multirow{4}{*}{$\begin{array}{l}\text { América } \\
\text { del } \\
\text { Norte } \\
\text { (Cont.) }\end{array}$} & $\begin{array}{l}\text { Recursos para la implementa- } \\
\text { ción de un Site Search en la } \\
\text { Universidad de Arizona }\end{array}$ & $\begin{array}{l}\text { Http:/ / dizzy.library.arizona.edu/ } \\
\text { sitesearch/ welcome.html }\end{array}$ \\
\hline & $\begin{array}{l}\text { Red de Información en Ever- } \\
\text { glade y Biblioteca Digital }\end{array}$ & http:/ / everglades.fiu.edu/ \\
\hline & Scout Report Signpost & $\begin{array}{l}\text { Http:/ / www.signpost.org/ signpost/ } \\
\text { index.html }\end{array}$ \\
\hline & $\begin{array}{l}\text { Search Engine and Web Direc- } \\
\text { tory for British Columbia, Ca- } \\
\text { nada }\end{array}$ & http:/ / www.searchbc.com \\
\hline $\begin{array}{l}\text { America } \\
\text { Latina }\end{array}$ & $\begin{array}{l}\text { Proyecto: Latin America on } \\
\text { National Centres of Antarctic } \\
\text { Data Antarctic. (Países partici- } \\
\text { pantes: Argentina, Brazil, Chile, } \\
\text { Perú, Uruguay). }\end{array}$ & $\begin{array}{l}\text { Http:/ / www.jcadm.scar.org/ Reports/ } \\
\text { JCAD M_Samerican_workshop } \\
\text { English.htm }\end{array}$ \\
\hline México & $\begin{array}{l}\text { El modelo de metadatos carto- } \\
\text { gráficos para el sistema de in- } \\
\text { formación virtual para la toma } \\
\text { de decisiones para el cambio } \\
\text { climático global }\end{array}$ & $\begin{array}{l}\text { Instituto Tecnológico de Estudios Superio- } \\
\text { res de Monterrey - Morelos. Líder Técnico } \\
\text { del Proyecto. }\end{array}$ \\
\hline \multirow{5}{*}{ Australia } & Australian Metaweb Project & $\begin{array}{l}\text { Http:/ / www.dstc.edu.au/ Research/ } \\
\text { Projects/ metaweb/ }\end{array}$ \\
\hline & $\begin{array}{l}\text { Centro Australiano de Investi- } \\
\text { gación y Colaboración en G eo- } \\
\text { dinámica. }\end{array}$ & http:/ / www.agcrc.csiro.au \\
\hline & $\begin{array}{l}\text { The Distributed Systems Te- } \\
\text { chnology Centre }\end{array}$ & http:/ / www.dsct.edu.au/ RDU/ \\
\hline & $\begin{array}{l}\text { EdNA (Education Network } \\
\text { Australia) }\end{array}$ & $\begin{array}{l}\text { Htpp:/ / www.edna.edu.au/ edna/ owa/ } \\
\text { info.getpage?sp=auto\&pagecode= }=5210\end{array}$ \\
\hline & A Mathematics Preprint Index & http:/ / www.dstc.edu.au/ D C4/ roland/ \\
\hline
\end{tabular}




\begin{tabular}{|c|c|c|}
\hline PAís & PROYECTO & DIRECCIÓN \\
\hline \multirow{4}{*}{$\begin{array}{l}\text { Australia } \\
\text { (Cont.) }\end{array}$} & Medio Ambiente de Australia & http:/ / www.environment.gov.au/ \\
\hline & $\begin{array}{l}\text { Proyecto Metadato de la Biblio- } \\
\text { teca del Estado de Queesland }\end{array}$ & $\begin{array}{l}\text { Http:/ / www.slq.qld.gov.au/ meta/ } \\
\text { overview.htm }\end{array}$ \\
\hline & Proyecto Pandora & $\begin{array}{l}\text { Http:/ / www.nla.gov.au/ policy/ } \\
\text { pandje97.html }\end{array}$ \\
\hline & Red de Educación de Australia & $\begin{array}{l}\text { Http:/ / otfe.vic.guv.edu.au/ edna/ } \\
\text { ds5edna.htm }\end{array}$ \\
\hline \multirow{10}{*}{ Europa } & $\begin{array}{l}\text { Agencia de Noticias para Bi- } \\
\text { bliotecas }\end{array}$ & http:/ / www.sbu.ac.uk/ litc/ newsagent/ \\
\hline & $\begin{array}{l}\text { AHD S Artes y Humanidades } \\
\text { Servicio de D atos }\end{array}$ & http:/ / ahds.as.uk/ \\
\hline & $\begin{array}{l}\text { Arte, Diseño, Arquitectura y } \\
\text { Entrada de Medios de Informa- } \\
\text { ción y el Servicio de Datos de } \\
\text { Arte Visual }\end{array}$ & http:/ / adam.ac.uk/ \\
\hline & $\begin{array}{l}\text { Biblioteca Electrónica de Imá- } \\
\text { genes para Europa }\end{array}$ & http:/ / severn.dmu.ac.uk/ elise/ \\
\hline & $\begin{array}{l}\text { Biblioteca Electrónica de Vi- } \\
\text { sualización }\end{array}$ & http:/ / visinfo.zib.de/ \\
\hline & $\begin{array}{l}\text { Biblioteca Nacional de Holanda } \\
\text { [Koninklijke Bibliotheek] }\end{array}$ & http:/ / www.konbib.nl/ \\
\hline & BN: O Projecto MALVINE & $\begin{array}{l}\text { Http:/ / www.bn.pt/ org/ inv_coop/ } \\
\text { malvine/ index.html }\end{array}$ \\
\hline & $\begin{array}{l}\text { CISMeF (Catálogo e Indice de } \\
\text { Sitios de Salud en idioma fran- } \\
\text { cés }\end{array}$ & http:/ / www.chu-rouen.fr/ ssf.html \\
\hline & The D esire Project & $\begin{array}{l}\text { Http:/ / www.nic.surfnet.nl/ surfnet/ } \\
\text { projects/ desire/ }\end{array}$ \\
\hline & $\begin{array}{l}\text { Dirección de Información } \\
\text { Electrónica y Metadatos en Fí- } \\
\text { sica }\end{array}$ & $\begin{array}{l}\text { Http:/ / www.physik.uni-oldenburg.de/ } \\
\text { PhysNet/ }\end{array}$ \\
\hline
\end{tabular}




\begin{tabular}{|c|c|c|}
\hline PAís & PROYECTO & DIRECCIÓN \\
\hline \multirow{15}{*}{$\begin{array}{l}\text { E uropa } \\
\text { (Cont.) }\end{array}$} & $\begin{array}{l}\text { DONOR (Directorio Holandés } \\
\text { de Recursos en Línea }\end{array}$ & $\begin{array}{l}\text { Http:/ / www.konbib.nl/ donor/ } \\
\text { index-en.html }\end{array}$ \\
\hline & $\begin{array}{l}\text { EULER (Bibliotecas Europeas y } \\
\text { Recursos Electrónicos en Cien- } \\
\text { cias Matemáticas }\end{array}$ & http:/ / www.emis.de/ projects/ EULER/ \\
\hline & $\begin{array}{l}\text { French National Mathematical } \\
\text { Preprint and Thesis Project }\end{array}$ & $\begin{array}{l}\text { Http:// www-mathdoc.ujf-grenoble.fr/ } \\
\text { math-prepub/ }\end{array}$ \\
\hline & $\begin{array}{l}\text { IND O REG: Internet D ocument } \\
\text { Registration }\end{array}$ & http:/ / www.purl.dk/ rapport/ html.uk/ \\
\hline & $\begin{array}{l}\text { Información de Temas An- } \\
\text { glo-Americanos sobre Historia, } \\
\text { Literatura, Ciencias de la Tierra, } \\
\text { Matemáticas. }\end{array}$ & http:/ / www.sub.uni-goettingen.de/ ssgfi/ \\
\hline & $\begin{array}{l}\text { Learning D irect Metadata Pro- } \\
\text { jekt (UK) }\end{array}$ & Http:/ / www.learningdirect.org/ \\
\hline & Math-Net & http:/ / elib.zib.de/ math-net/ \\
\hline & $\begin{array}{l}\text { Metadata Server of the SUB } \\
\text { Göettingen }\end{array}$ & http:/ / www2.sub.uni-goettingen.de \\
\hline & $\begin{array}{l}\text { MMM-interface for Creation of } \\
\text { DC-Metadata Files }\end{array}$ & $\begin{array}{l}\text { Http:/ / www.mathematik.uni-osnabrueck.de/ } \\
\text { projects/ Meta/ }\end{array}$ \\
\hline & Monticello Project & $\begin{array}{l}\text { Http:/ / www.solinet.net/ monticello/ } \\
\text { monticel.htm }\end{array}$ \\
\hline & Netpublikationer & http:/ / www.fsk.dk/ fsk/ publ/ online-pub/ \\
\hline & NewsAgent for Libraries & $\begin{array}{l}\text { Http:/ / www.ukoln.ac.uk/ metadata/ } \\
\text { NewsAgent/ }\end{array}$ \\
\hline & Nordic Metadata Project & http:/ / linnea.Helsinki.fi/ meta/ present.html \\
\hline & Nordic Web Index & $\begin{array}{l}\text { Http:/ / nwi.ub2.lu.se/ } \\
\text { http:/ / nwi.dtv.dk/ nwi_info.html\#metadata }\end{array}$ \\
\hline & $\begin{array}{l}\text { NWI Dublin Core D atabase } \\
\text { for D enmark }\end{array}$ & $\begin{array}{l}\text { http:/ / gungner.ub2.lu.se/ cgi- } \\
\text { bin/ egwcgi/ 57697/ meta- } \\
\text { query.egw;/ -1+nwi.dtv.dk:5555/ md }\end{array}$ \\
\hline
\end{tabular}




\begin{tabular}{|c|c|c|}
\hline PAÍs & PROYECTO & DIRECCIÓN \\
\hline \multirow{12}{*}{$\begin{array}{l}\text { E uropa } \\
\text { (Cont.) }\end{array}$} & $\begin{array}{l}\text { NWI D ublin Core D atabase } \\
\text { for Sweden }\end{array}$ & $\begin{array}{l}\text { Http:/ / gungner.ub2.lu.se/ cgi-bin/ egwcgi/ } \\
\text { 57696/ metaquery.egw;/ -1+desire2. } \\
\text { lub.se:2124/ swemeta }\end{array}$ \\
\hline & Proyecto BIBLINK & http:/ / hosted.lu.se.ukoln.ac.uk/ biblink/ \\
\hline & Proyecto DESIRE & $\begin{array}{l}\text { Http:/ / www.nic.surfnet.nl/ surfnet/ } \\
\text { projects/ desire/ desire.html }\end{array}$ \\
\hline & $\begin{array}{l}\text { Proyecto Metadato [Metada- } \\
\text { ten-Projekt] }\end{array}$ & http:/ / www2.sub.uni-goettingen.de \\
\hline & $\begin{array}{l}\text { Red de Bibliotecas del Suroeste } \\
\text { de Alemania [Bibliotheksservi- } \\
\text { ce-Zentrum (BSZ) Baden- } \\
\text { Wuerttemberg (Sudwestdeuts- } \\
\text { cher Bibliotheksverbund- } \\
\text { SWB-Verbund) }\end{array}$ & $\begin{array}{l}\text { Http:/ / www.swbv.uni-konstanz.de/ } \\
\text { wwwroot/ s71800_d.html }\end{array}$ \\
\hline & $\begin{array}{l}\text { Resource for Urban D esign In- } \\
\text { formation }\end{array}$ & http:/ / rudi.herts.ac.uk/ catsrch/ catsrch.html \\
\hline & $\begin{array}{l}\text { The ROAD S Project: Resources } \\
\text { Organisation and D iscovery in } \\
\text { Subject-based Services }\end{array}$ & http:/ / ukoln.bath.ac.uk/ roads/ \\
\hline & SAFARI & http:/ / safari.hsv.se/ index.html.en \\
\hline & $\begin{array}{l}\text { SCRAN (Red Escocesa de Ac- } \\
\text { ceso a Recursos Culturales) }\end{array}$ & http:/ / www.scran.ac.uk \\
\hline & $\begin{array}{l}\text { Servidor Alemán de Recursos } \\
\text { Educacionales [D eutscher Bil- } \\
\text { dungs-Server] }\end{array}$ & http:/ / dbs.schule.de/ indexe.html \\
\hline & Swedish EnviroNet & http:/ / smn.environ.se/ \\
\hline & $\begin{array}{l}\text { UKO LN The UK O ffice for Li- } \\
\text { brary and Information Net- } \\
\text { working }\end{array}$ & http:/ / www.ukoln.ac.uk/ \\
\hline
\end{tabular}

